\title{
Personalized perioperative medicine: a scoping review of personalized assessment and communication of risk before surgery
}

\section{La médecine périopératoire personnalisée : une étude de portée sur l'évaluation et la communication des risques personnalisées avant la chirurgie}

\author{
Emma P. Harris, MD • David B. MacDonald, MD, FRCPC • \\ Laura Boland, MSc-SLP-C, PhD • Sylvain Boet, MD, PhD • \\ Manoj M. Lalu, MD, PhD, FRCPC • Daniel I. McIsaac, MD, MPH, FRCPC
}

Received: 25 September 2018/Revised: 10 March 2019/Accepted: 11 March 2019/Published online: 25 June 2019

(C) Canadian Anesthesiologists' Society 2019

\begin{abstract}
Background Personalized medicine aims to improve outcomes through application of therapy directed by individualized risk profiles. Whether personalized risk assessment is routinely applied in practice is unclear; the impact of personalized preoperative risk prediction and communication on outcomes has not been synthesized. Our
\end{abstract}

This article is accompanied by an editorial. Please see Can J Anesth 2019; 66: this issue.

E. P. Harris, MD

Departments of Anesthesiology \& Pain Medicine, University of Ottawa and The Ottawa Hospital, Ottawa, Canada

D. B. MacDonald, MD, FRCPC

Department of Anesthesia, Pain Management and Perioperative

Medicine, Dalhousie University, Halifax, Canada

L. Boland, MSc-SLP-C, PhD

Population Health, Faculty of Health Sciences, University of Ottawa, Ottawa, Canada

S. Boet, MD, PhD

Departments of Anesthesiology \& Pain Medicine, University of Ottawa and The Ottawa Hospital, Ottawa, Canada

Ottawa Hospital Research Institute, Ottawa, Canada

Department of Innovation in Medical Education, University of Ottawa, Ottawa, Canada

M. M. Lalu, MD, PhD, FRCPC

Departments of Anesthesiology \& Pain Medicine, University of Ottawa and The Ottawa Hospital, Ottawa, Canada objective was to perform a scoping review to examine the extent, range, and nature of studies where personalized risk was evaluated preoperatively and communicated to the patient and/or healthcare professional.

Methods A systematic search was developed, peerreviewed, and applied to Embase, Medline, CINAHL, and Cochrane databases to identify studies of individuals having or considering surgery, where a process to assess personalized risk was applied and where these estimates were communicated to a patient and/or healthcare

Ottawa Hospital Research Institute, Ottawa, Canada

Department of Cellular and Molecular Medicine, University of Ottawa, Ottawa, Canada

D. I. McIsaac, MD, MPH, FRCPC ( $\varangle)$

Departments of Anesthesiology \& Pain Medicine, University of Ottawa and The Ottawa Hospital, Ottawa, Canada

e-mail:dmcisaac@toh.ca

Ottawa Hospital Research Institute, Ottawa, Canada

School of Epidemiology, \& Public Health, University of Ottawa, Ottawa, ON, Canada

Departments of Anesthesiology \& Pain Medicine, The Ottawa Hospital, Room B311, 1053 Carling Ave, Ottawa, ON K1Y 4E9, Canada 
professional. All stages of the review were completed in duplicate. We narratively synthesized and described identified themes.

Results We identified 796 studies; 24 underwent full-text review. Seven studies were included; one communicated personalized risk to patients, four to a healthcare professional, and two to both. Cardiac $(n=2)$ and orthopedic surgery $(n=2)$ were the most common surgical specialties. Four studies used electronic risk calculators, and three used paper-based tools. Personalized preoperative risk assessment and communication may improve accuracy of information provided to patients, improve consent processes, and influence length of stay. Methodologic weaknesses in study design were common.

Conclusions Personalized preoperative risk assessment and communication may improve patient and system outcomes. This evidence is limited, however, by weaknesses in study design. Appropriately powered, low risk of bias evaluation of personalized risk communication before surgery is needed.

\section{Résumé}

Contexte La médecine personnalisée a pour objectif d'améliorer les pronostics en appliquant un traitement basé sur des profils de risque individualisés. Nous ne savons pas si l'évaluation du risque personnalisé est fréquemment utilisée dans la pratique; il n'existe pas de synthèse concernant l'impact de la prédiction et de la communication personnalisée du risque préopératoire sur les pronostics. Notre objectif était de réaliser une étude de portée (scoping review) afin d'examiner l'ampleur, l'envergure et la nature des études dans lesquelles le risque personnalisé avait été évalué en préopératoire et communiqué au patient et/ou au professionnel de la santé. Méthode Une recherche systématique a été mise au point, révisée par les pairs et appliquée aux bases de données Embase, Medline, CINAHL et Cochrane afin d'identifier les études portant sur des personnes ayant subi ou envisageant de subir une chirurgie et pour lesquelles un processus d'évaluation personnalisée des risques avait été appliqué, et que ces estimations avaient été communiquées au patient et/ou à un professionnel de la santé. Toutes les étapes de révision ont été réalisées en double. Nous avons effectué une synthèse narrative et décrit les thèmes identifiés.

Résultats Nous avons identifié 796 études; le texte intégral de 24 d'entre elles a été passé en revue. Sept études ont été incluses; le risque personnalisé a été communiqué aux patients dans une étude, à un professionnel de la santé dans quatre études, et aux deux instances dans deux études. Les spécialités chirurgicales les plus courantes étaient la chirurgie cardiaque $(n=2)$ et orthopédique $(n=2)$. Quatre études ont utilisé des calculatrices de risque électroniques, et trois se sont appuyées sur des outils sur papier. L'évaluation et la communication personnalisées du risque préopératoire pourraient améliorer la précision des informations présentées aux patients, améliorer les processus de consentement et influencer la durée de séjour. Les faiblesses méthodologiques dans la conception des études étaient fréquentes.

Conclusion L'évaluation et la communication personnalisées $d u$ risque préopératoire pourraient améliorer les pronostics individuels des patients et systémiques. Les données probantes sont toutefois limitées en raison de faiblesses dans la conception des études. Il est nécessaire de procéder à une évaluation de la communication personnalisée $d u$ risque avant une chirurgie comportant un faible risque de biais et bénéficiant d'un échantillon adéquat.

Personalized medicine seeks to identify individuals or subpopulations who may be particularly susceptible to a disease or outcome, or who may differentially respond to treatment, through formalized risk stratification. By classifying individuals' risk profiles, application of healthcare interventions and therapies can then be directed by individual profiles. ${ }^{1-3}$

Nevertheless, despite substantial promise based on advances in data science and genomics, personalized approaches to perioperative care have not been widely developed or implemented. Personalized medicine could play an important role in improving perioperative care; approximately $40 \%$ of patients having major surgery experience an adverse event ${ }^{4} ; 10-15 \%$ have a serious complication and $1-2 \%$ die within 30 days of surgery. 5

Individual characteristics explain much of the variation in risk between people. For example, using the National Surgical Quality Improvement Program's (NSQIP) Universal Risk Calculator, ${ }^{7}$ a 50 -yr-old female having colorectal surgery with no comorbidities has a $9 \%$ risk of serious postoperative complications, a near $0 \%$ risk of death, and an expected hospital stay of five days. The same surgery in a 75-yr-old male with diabetes and chronic obstructive pulmonary disease, who smokes and is partially dependent on others, carries a 39\% risk of serious complications, a $2 \%$ risk of death, and an expected hospital stay of 13 days. Without detailed knowledge of these risk profiles, healthcare providers may be unable to plan and enact care processes and pathways specifically tailored to modify the unique risks faced by each patient.

Patients undergoing surgery are exposed to variable risk and need to be informed of their personalized risk 
Table 1 Research question

\begin{tabular}{ll}
\hline Population & Adults considering or planning to have surgery and healthcare professionals caring for such patients \\
Intervention & Application of a process to calculate and communicate personalized risk to the patient or healthcare professional \\
Comparator & Any \\
Outcomes & Institute for Healthcare Improvement's Triple Aim Framework of improved health, lower costs, and better experience
\end{tabular}

preoperatively to help guide their autonomy in decisionmaking. ${ }^{8}$ Despite clear evidence that patients desire more information prior to surgery, this "need to know" is typically underestimated by clinicians. 9,10 When information is provided, risks may not be clearly communicated $^{11}$ and this may negatively impact treatment decisions. $^{12}$ Limited communication and understanding of risk raise serious concerns regarding whether "informed consent" can really be achieved. A health treatment plan that is inconsistent with the patient's informed preferences can have negative impacts on the patient (e.g., regret, decisional conflict, or blaming the healthcare provider for undesired consequences) and health system (e.g., overuse of unnecessary interventions). ${ }^{13,14}$

Because there appears to be a discrepancy between the widespread availability of preoperative risk stratification tools ${ }^{15}$ and the apparent lack of utilization of these tools to provide individualized risk communication to patients and their healthcare professionals, which is a barrier to personalized medicine, we sought to systematically identify studies where: 1) methods to calculate personalized preoperative risk were described and 2) these risks were communicated to either the patient, healthcare professional, or both. We further sought to synthesize the impact of personalized preoperative risk prediction and communication on patient and health system outcomes.

\section{Methods}

This study followed the recommendations for conduct of scoping reviews. ${ }^{16,17}$ Because personalized perioperative medicine is a relatively new area of study with complex applications and heterogeneous approaches, we chose a scoping review approach to understand the extent, nature, and range of investigations in this area. Scoping reviews allow incorporation of a wide range of study designs and identification of key knowledge gaps, and should inform refinement of future research inquiries. ${ }^{16,18}$

\section{Stage 1: identifying the research question}

We iteratively developed a broad research question to identify relevant studies. Our population was adults $(\geq 18$ yr old) considering or planning to have surgery, and perioperative healthcare professionals (such as a physician, nurse, or allied health professional). Originally, we only included patients, however, through iteration we broadened this to healthcare professionals as our initial review identified few studies of patient-oriented communication $(n=3)$. The intervention was the application of a process to calculate and communicate personalized risk to the patient or healthcare professional. No limitations were placed on the type of comparator, risk calculation method, or study design. Outcomes were categorized according to the Institute for Healthcare Improvement's (IHI) Triple Aim Framework of improved health, lower costs, and better experience. ${ }^{19}$ Our specific research question is provided in Table 1.

Stage 2: identifying relevant studies

In collaboration with an information specialist, a systematic search was developed and underwent the Peer Review of Electronic Search Strategies process. ${ }^{20}$ The strategy was applied to Embase, Medline, CINAHL, and Cochrane databases from inception and without language restrictions. The first search was performed in February 2017 and it was updated in November 2017. The strategy combined broad terms for surgical procedures, risk assessment or communication, decision-making, consent or counselling, as well as personalized, patient- or personcentred care (Appendix A). Full-text articles and conference abstracts were eligible for inclusion.

Stage 3: study selection

All titles, abstracts, and full texts were reviewed independently (D.B.M., E.P.H., D.I.M.) and in duplicate using Distiller SR (Evidence Partners, Ottawa, ON, Canada). Authors met prior to beginning the study to discuss and operationalize inclusion criteria, and at the completion of review to resolve any discrepancies by consensus. Studies were excluded if they did not describe a process to calculate personalized risk and describe how this risk was then communicated to a patient or healthcare professional. In several studies, the healthcare professional performing the risk assessment (i.e., inputting the risk factors) was also the one who received the results 


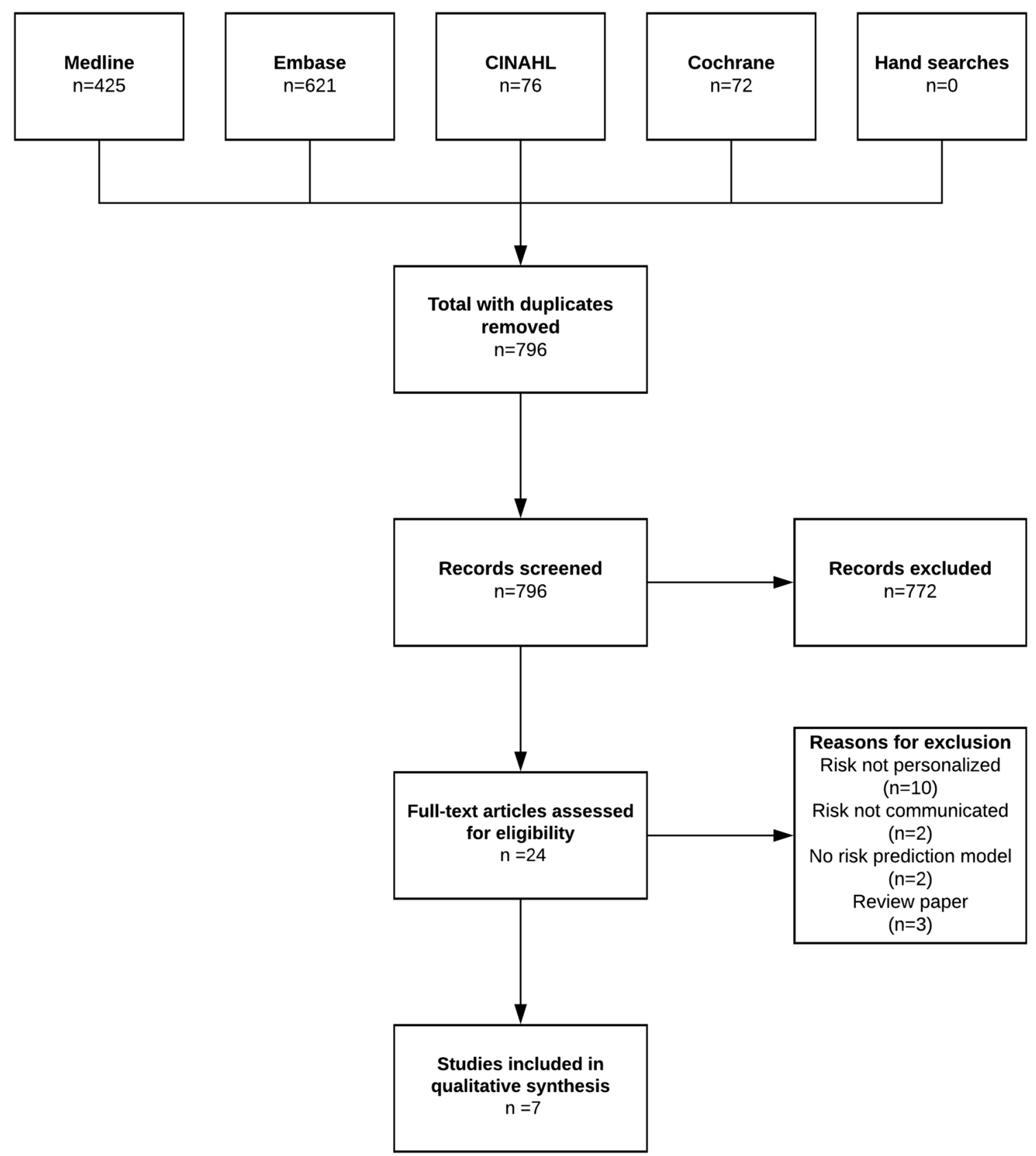

Figure Preferred reporting items for systematic reviews and meta analyses flow diagram

(communication of risk). These were still considered to have met the inclusion criteria when this was performed systematically, as the risk prediction from the assessment tool was communicated to the healthcare professional. Reference lists of all included studies were reviewed to identify further studies that may have been missed by our structured search. Because of the limited number of identified studies, we decided to include publications for which there was only an abstract available.
Stage 4: data extraction

A unique data extraction form was developed for our study. The form was piloted prior to full implementation. From each study, we identified publication characteristics, study design and sample characteristics, the surgical population studied, risk model used to estimate personalized risk, actions taken to communicate risk, and outcome(s) measured. Data were extracted by one author (E.P.H) and checked for accuracy by a second author (D.I.M.). 
Stage 5: summarizing and reporting results

Our data summary and analysis consisted of several phases. First, we identified the following themes as being key to this area of research: 1) the types of patients and surgical procedures that have been studied; 2) the process of risk calculation (i.e., the risk models, tools used, and communication [i.e., how and to whom]); and 3) the results of the risk calculation and communication process (i.e., outcomes).

To summarize our data, we calculated descriptive statistics for the sample of included studies, including the proportion of studies featuring specific patient and procedural characteristics. We then calculated the proportion of studies that used a paper-based $v s$ electronic process and described the risk models used and their underlying derivation and validation processes. We determined how many studies communicated risks to patients $v s$ a healthcare professional, and assessed how many studies specified an outcome in each domain of the IHI Triple Aim Framework. ${ }^{19}$ Guided by each identified theme, we also provided a narrative synthesis to place our findings in the context of our overall objectives and to frame our findings regarding future research. As the main purpose of scoping reviews is not to critically appraise the risk of bias of the evidence, the risk of bias for each included study was not assessed. ${ }^{21}$ Nevertheless, we did comment on methodologic weaknesses across studies to inform future research.

\section{Mobile technology applications}

After starting our review, we also recognized the related importance of documenting mobile applications available for preoperative risk calculation. Therefore, a single author (E.P.H.) reviewed the Google Play and Apple App Stores to identify Android and iOS applications that can be used to calculate patient-level preoperative risk. This search was performed in September 2018 using the terms "surgical risk", "peri-operative risk", "peri-operative risk calculator", and "surgery risk". Application descriptions were reviewed and included if they described a platform that allowed input of patient and/or surgical characteristics and generated an estimated risk of a postoperative outcome. Applications were not downloaded or tested.

\section{Results}

A total of 796 unique citations were identified through our search. After title and abstract review, 24 were advanced to full-text review. Of those, another 17 studies were eliminated, leaving seven unique citations for data extraction and analysis (Figure, including summary of reasons for exclusion at full-text review). A study-level description of reasons for full-text exclusion is provided in Appendix B. Four studies were only available as conference abstracts. A review of the Google Play and Apple App Stores identified 22 unique perioperative risk calculators available in the Android and/or iOS environment (Appendix C).

\section{Study designs and characteristics}

Two studies (28.6\%) involved cardiac surgery, ${ }^{22,23}$ and two involved orthopedic surgery $(28.6 \%)^{24,25}$ Other surgical specialties included gynecology $(14.3 \%)^{26}$ and general surgery $(14.3 \%){ }^{27}$ In one study, the surgical population was not reported $(14.3 \%){ }^{28}$ Study characteristics are described in Table 2. In total, included studies involved 1,637 participants. Studies were conducted in Canada, Germany, the United Kingdom, and the United States. The oldest study was published in 2005; the most recent in 2017. Study designs were heterogeneous. One study was a randomized controlled trial; other designs included case series $(n=3 / 8)$, case report $(n=1 / 8)$, and before-and-after designs $(n=2 / 8)$.

\section{The process of risk communication}

Four of the seven studies described an application where personalized risk was only communicated to a healthcare professional; in three studies, risk was also communicated to patients. Two studies used a paper-based tool, ${ }^{23,24}$ four used an electronic approach, ${ }^{22,26-28}$ and one did not report this aspect of their process. ${ }^{25}$ Two studies reported using a risk model that was externally validated. ${ }^{26,27}$ These validated models included Portsmouth-Physiological and Operative Severity Score for the enUmeration of Mortality (known as P-POSSUM: predicts morbidity and mortality in patients undergoing major surgical procedures $)^{29,30}$ and the individualized prediction model for de novo stress urinary incontinence after vaginal pelvic organ prolapse surgery. ${ }^{31}$ Three studies derived their own models and applied them to their intervention without documented validation..$^{22,24,25}$ Two studies did not report details of the model used (Table 3). ${ }^{23,28}$

\section{Study outcomes}

Based on the IHI's Triple Aim framework, one study had an outcome in the health domain (compliance to consultant involvement guidelines in high-risk cases), ${ }^{27}$ two had a primary outcome in the cost domain (length of stay), ${ }^{24,25}$ and three had an outcome in the experience domain (patient satisfaction, decisional regret, visit length, patient 
Table 2 Included studies and description of interventions and outcomes

\begin{tabular}{|c|c|c|c|c|c|c|c|}
\hline Reference & $\begin{array}{l}\text { Surgical } \\
\text { population }\end{array}$ & Design & Study size & $\begin{array}{l}\text { Risk assessor and } \\
\text { source of predictor } \\
\text { variables }\end{array}$ & $\begin{array}{l}\text { Target for risk } \\
\text { communication }\end{array}$ & Interventions & Outcome(s) \\
\hline $\begin{array}{l}\text { Aggarwal } \\
\text { (2014) } \\
\text { Colorectal } \\
\text { Disease }\end{array}$ & General & Case series & $n=290$ & $\begin{array}{l}\text { Physician inputs } \\
\text { clinical } \\
\text { variables into } \\
\text { web-based risk } \\
\text { calculator }\end{array}$ & Physician & $\begin{array}{l}\text { - Prompts surgeon and } \\
\text { anesthesiologist when } \\
\text { predicted mortality } \\
>5 \%\end{array}$ & $\begin{array}{l}\text { - High compliance } \\
\text { to guidelines } \\
\text { - High levels of } \\
\text { consultant } \\
\text { involvement in } \\
\text { high risk } \\
\text { individuals (91\% } \\
\text { anesthesia, 97\% } \\
\text { surgery) }\end{array}$ \\
\hline $\begin{array}{l}\text { Bihorac } \\
\text { (2013) Crit } \\
\text { Care Med }\end{array}$ & $\begin{array}{l}\text { Not } \\
\quad \text { reported }\end{array}$ & Case series & $n=50$ & $\begin{array}{l}\text { Research team } \\
\text { inputs } \\
\text { preoperative } \\
\text { clinical data }\end{array}$ & Physician & $\begin{array}{l}\text { - Electronic risk } \\
\text { calculator presents risk } \\
\text { estimates for organ } \\
\text { complications or } \\
\text { intensive care unit } \\
\text { admission to physicians }\end{array}$ & $\begin{array}{l}\text { - ePRINT more } \\
\text { accurate than } \\
\text { physicians } \\
\text { - Physician } \\
\text { prognostic } \\
\text { accuracy } \\
\text { improved after } \\
\text { knowledge } \\
\text { exchange }\end{array}$ \\
\hline $\begin{array}{l}\text { Macdonald } \\
\text { (2005) } \\
\text { Journal of } \\
\text { Orthopedic } \\
\text { Nursing }\end{array}$ & Orthopedic & Before-after & $n=1,063$ & $\begin{array}{l}\text { Patient fills out } \\
\text { questionnaire } \\
\text { then nurse } \\
\text { reviews } \\
\text { questionnaire } \\
\text { and calculates } \\
\text { risk }\end{array}$ & Interdisciplinary & $\begin{array}{l}\text { - Individual risk factors } \\
\text { used to trigger } \\
\text { preoperative allied } \\
\text { health optimization }\end{array}$ & $\begin{array}{l}\text { - Shorter length of } \\
\text { stay }\end{array}$ \\
\hline $\begin{array}{l}\text { Punt (2017) } \\
\text { Federal } \\
\text { Health } \\
\text { Gazette }\end{array}$ & Orthopedic & Case report & $n=1$ & $\begin{array}{l}\text { Physiotherapist } \\
\text { uses } \\
\text { preoperative } \\
\text { conditions and } \\
\text { performance } \\
\text { measures to } \\
\text { calculate risk }\end{array}$ & Interdisciplinary & $\begin{array}{l}\text { - Risk assessment tool } \\
\text { used to identify } \\
\text { individuals at risk for } \\
\text { delayed recovery to } \\
\text { trigger a physiotherapy } \\
\text { intervention }\end{array}$ & $\begin{array}{l}\text { - Shorter length of } \\
\text { stay }\end{array}$ \\
\hline $\begin{array}{c}\text { Gainer (2016) } \\
\text { Can Journal } \\
\text { Cardiology }\end{array}$ & Cardiac & Before-after & $n=200$ & $\begin{array}{l}\text { Research team } \\
\text { populates } \\
\text { individualized } \\
\text { risk assessment } \\
\text { with patient data }\end{array}$ & Patient & $\begin{array}{l}\text { - Paper-based patient } \\
\text { decision aid populated } \\
\text { with personalized risk } \\
\text { - Surgeons trained in } \\
\text { shared decision making } \\
\text { - Decisional coach } \\
\text { available }\end{array}$ & $\begin{array}{l}\text { - Improved patient } \\
\text { comprehension of } \\
\text { risk } \\
\text { - No difference in } \\
\text { anxiety and } \\
\text { depression scores, } \\
\text { and decisional } \\
\text { conflict }\end{array}$ \\
\hline $\begin{array}{l}\text { Malenka } \\
\text { (2011) Circ } \\
\text { Cardiovasc } \\
\text { Qual } \\
\text { Outcomes }\end{array}$ & Cardiac & Case series & $\begin{array}{l}\text { Not } \\
\quad \text { reported }\end{array}$ & $\begin{array}{l}\text { Electronic and } \\
\text { physicians } \\
\text { inputted } \\
\text { variables into } \\
\text { populate risk } \\
\text { model }\end{array}$ & Patient & $\begin{array}{l}\text { - Consent documents } \\
\text { populated with } \\
\text { personalized risk }\end{array}$ & $\begin{array}{l}\text { - Physicians found } \\
\text { prototype simple } \\
\text { to use } \\
\text { - Patients thought } \\
\text { the intervention } \\
\text { stimulated } \\
\text { conversations } \\
\text { with clinicians }\end{array}$ \\
\hline $\begin{array}{l}\text { Miranne } \\
\quad(2017) \\
\text { Female } \\
\text { Pelvic Med } \\
\text { Reconstr } \\
\text { Surg }\end{array}$ & Gynecology & $\begin{array}{l}\text { Randomized- } \\
\text { controlled } \\
\text { trial }\end{array}$ & $n=33$ & $\begin{array}{l}\text { Physicians access } \\
\text { online risk } \\
\text { calculator to } \\
\text { input variables }\end{array}$ & Patient & $\begin{array}{l}\text { - Standard counselling } \\
\text { and risk calculator } v s \\
\text { standard counselling }\end{array}$ & $\begin{array}{l}\text { - No difference in } \\
\text { satisfaction or } \\
\text { decisional regret } \\
\text { at three months } \\
\text { after surgery } \\
\text { - No difference in } \\
\text { visit length }\end{array}$ \\
\hline
\end{tabular}


Table 3 Included studies risk models

\begin{tabular}{|c|c|c|c|c|c|c|c|}
\hline & Reference & $\begin{array}{l}\text { Risk } \\
\text { calculator } \\
\text { format }\end{array}$ & Risk model (variables) & $\begin{array}{l}\text { Outcome(s) } \\
\text { predicted }\end{array}$ & Validation & Discrimination & Calibration \\
\hline \multirow[t]{4}{*}{$\begin{array}{l}\text { Clinician } \\
\text { oriented }\end{array}$} & $\begin{array}{l}\text { Aggarwal } \\
(2014)\end{array}$ & - Electronic & $\begin{array}{l}\text { P-POSSUM (age, physiologic } \\
\text { parameters, lab results, } \\
\text { operative parameters) }\end{array}$ & $\begin{aligned} \text { - } & \text { 30-day } \\
& \text { mortality }\end{aligned}$ & External & $\begin{array}{l}\mathrm{AUC}=0.65- \\
\quad 0.82\end{array}$ & $\mathrm{HL}<0.001-0.25$ \\
\hline & $\begin{array}{l}\text { Bihorac } \\
\quad(2013)\end{array}$ & - Electronic & $\begin{array}{l}\text { - ePRINT (preoperative clinical } \\
\text { data) }\end{array}$ & $\begin{array}{l}\text { - ICU admission } \\
\text { • AKI }\end{array}$ & $\begin{array}{l}\text { Not } \\
\text { reported }\end{array}$ & $\begin{array}{l}\mathrm{AUC}=0.90 \\
\text { for ICU and } \\
0.83 \text { for } \\
\text { AKI }\end{array}$ & Not reported \\
\hline & $\begin{array}{l}\text { MacDonald } \\
\text { (2005) }\end{array}$ & - Paper & $\begin{array}{l}\text { Patient questionnaire } \\
\text { (demographics, pain, } \\
\text { deconditioning, anemia, } \\
\text { comorbidities, social } \\
\text { supports) }\end{array}$ & $\begin{array}{l}- \text { Delayed } \\
\text { recovery }\end{array}$ & $\begin{array}{l}\text { Not } \\
\quad \text { reported }\end{array}$ & Not reported & Not reported \\
\hline & Punt (2017) & $\begin{array}{l}- \text { Not } \\
\text { reported }\end{array}$ & $\begin{array}{l}\text { - Multi-dimensional assessment } \\
\text { (physical testing, } \\
\text { demographics, medical } \\
\text { history, cognitive abilities) }\end{array}$ & $\begin{array}{l}\text { - Delayed } \\
\text { recovery }\end{array}$ & $\begin{array}{l}\text { Not } \\
\text { reported }\end{array}$ & Not reported & Not reported \\
\hline \multirow[t]{3}{*}{$\begin{array}{l}\text { Patient } \\
\quad \text { oriented }\end{array}$} & $\begin{array}{l}\text { Gainer } \\
\quad(2016)\end{array}$ & - Paper & $\begin{array}{l}\text { - Decision aid (demographics, } \\
\text { comorbidity status) }\end{array}$ & - Not specified & $\begin{array}{l}\text { Not } \\
\text { reported }\end{array}$ & Not reported & Not reported \\
\hline & $\begin{array}{r}\text { Malenka } \\
(2011)\end{array}$ & - Electronic & $\begin{array}{l}\text { Multivariable model (age, } \\
\text { gender, comorbidities, prior } \\
\text { intervention, coronary } \\
\text { anatomy, urgency) }\end{array}$ & $\begin{array}{l}\text { - Mortality } \\
\text { - Morbidity }\end{array}$ & $\begin{array}{l}\text { Not } \\
\text { reported }\end{array}$ & Not reported & Not reported \\
\hline & $\begin{array}{l}\text { Miranne } \\
\text { (2017) }\end{array}$ & - Electronic & $\begin{array}{l}\text { - Cleveland Clinic risk of de } \\
\text { novo stress incontinence } \\
\text { calculator (age, BMI, vaginal } \\
\text { births, diabetes) }\end{array}$ & $\begin{array}{l}\text { - New } \\
\text { postoperative } \\
\text { stress } \\
\text { incontinence }\end{array}$ & External & $\mathrm{AUC}=0.62$ & $\begin{array}{l}\text { Calibration plot- } \\
\text { predicted } \\
\text { probability exceeds } \\
\text { observed above } \\
0.50\end{array}$ \\
\hline
\end{tabular}

$\mathrm{AKI}=$ acute kidney injury; $\mathrm{AUC}=$ area under the curve $\mathrm{BMI}=$ body mass index $; \mathrm{HL}=$ Hosmer-Lemeshow $P$ value; $\mathrm{ICU}=$ intensive care unit

comprehension, and decisional quality [i.e., when a patient's values and preferences match their informed choice or informed preference-choice congruence], and quality of consent conversations; Table 1). ${ }^{2,23,26}$

In the four studies reporting healthcare professionaloriented risk communication, there was evidence of process and outcome improvements. Aggarwal et al. reported high levels of consultant surgeon and anesthesiologist perioperative participation $(91 \%$ and $97 \%$, respectively) after they were informed of patients' high mortality risk (P-POSSUM $>5 \%$ predicted mortality). ${ }^{27}$ Bihorac et al. found that presenting the risk of adverse effects estimates to physicians improved the accuracy of the physicians' risk prediction compared with their clinical impression. ${ }^{28}$ Macdonald et al. found that length of stay after hip and knee replacement was decreased by 0.6-0.7 days after risk assessment for delayed recovery was used to trigger educational and allied health interventions. ${ }^{24}$ Punt $e t$ al. used a paper-based risk assessment tool to identify patients who might benefit from a physiotherapist (intensive home training program); they report a patient exposed to this process who stayed 1.5-2 days less than individuals with comparable preoperative risk identified from the hospital database. None of these studies provided tests of statistical significance compared with a control group.

In three studies reporting patient-oriented risk calculation and communication, findings suggested improvements in the decision-making process and a positive impact on experience. Specifically, Gainer et al. found that personalized risk communication combined with decision aids and coaching lead to improvement in patient risk comprehension $(P<0.001)$ and that the decisionmaking process was more consistent with optimal shared decision-making $(P<0.05){ }^{23}$ Using an electronic risk calculator before cardiac procedures, Malenka et al. found that patients perceived an improvement in the quality of preoperative conversations, while physicians found the calculator easy to use (no comparative data were presented). ${ }^{22}$ Finally, using an electronic calculator to estimate the likely success of a mid-urethral sling in women with pelvic organ prolapse, Miranne et al. found no 
difference in patients' decision satisfaction three months after surgery. $^{26}$

\section{Discussion}

Following a broad, inclusive, and iterative search of the perioperative literature, this scoping review shows that personalized approaches to preoperative risk calculation are possible and may aid in preoperative decision-making and individualized care planning. We identified seven publications that described processes where personalized risks were calculated and communicated to a patient and/or healthcare professional. In three studies, personalized risk information was provided to patients, and in six, calculation and communication processes were evaluated to determine their impact on patient care and/or outcomes. Of note, sample sizes were small, most study designs not robust ( $n=1$ randomized trial) and four of the seven studies only had abstracts available. As patients and health care regulators continue to request and expect more personalized information, and as the field of perioperative medicine evolves, there appears to be a need and an opportunity to design, implement, and evaluate patientoriented personalized risk calculation and communication applications.

Preoperative risk stratification is an important part of anesthesia and perioperative medicine practice, as it can identify patients who warrant further investigations, interventions, or monitoring. ${ }^{15}$ Nevertheless, despite significant efforts to derive and validate many preoperative risk prediction models, ${ }^{7,29,32}$ the literature does not describe widespread uptake or clinical evaluation of these tools. A lack of comfort or perceived expertise on the part of clinicians has been identified as a possible barrier to effective risk communication to patients. ${ }^{33}$ In particular, challenges in understanding statistics and probabilities $^{33-35}$ may help to explain why risk communication from clinicians to patients tends to be based on verbal communication of subjective risk thresholds (i.e., low, medium, or high risk). ${ }^{11,33}$ Emerging information technology (i.e., mobile platforms such as tablets equipped with risk prediction apps) combined with the developing field of perioperative predictive modelling and knowledge of how to optimize patients' understanding of risk ${ }^{36}$ holds significant promise to improve the current state of personalized perioperative medicine. Nevertheless, based on our findings, this has yet to be routinely implemented.

Risk estimates are meaningless unless they are generated from a valid and accurate prediction model. Validation of risk prediction models (at least for binary outcomes such as death or complications) requires, at a minimum, evaluation of discrimination (i.e., does the model generate a higher probability of outcome for those who truly do experience the outcome compared with those who do not) and calibration (are the outcome probabilities calculated by the model [i.e., expected rates of outcomes] similar to those that actually occur [i.e., observed rates of outcomes]). ${ }^{37}$ The model should be re-tested using different data (i.e., not initially used to derive the model) to ensure that the accuracy of predicted values is not simply a result of the characteristics of the initial dataset. ${ }^{37}$ Nevertheless, despite availability of a growing number of validated preoperative risk scores, externally validated models were used in only two of the seven studies. ${ }^{26,27}$

Few electronic applications have been scientifically evaluated. Of the seven identified studies, four were electronic and none were optimized for mobile use. Electronic applications offer advantages over paper-based methods; patients' understanding of risk is improved when information is appropriately framed ${ }^{33}$ (e.g., absolute risk estimates, $^{38}$ pictorial representations, ${ }^{34,39}$ and personalization $)^{40}$ and this is ideally suited to an electronic format. None of the studies that we identified incorporated all of these principles, and only Malenka et $a .^{22}$ described optimization of risk communication (using absolute personalized estimates with denominators) in a fashion that would likely improve patient-level comprehension. Our review of Android and iOS applications shows that at least 22 electronic risk prediction apps are available, however, evaluation of their use in the clinical setting is clearly lacking. Of further importance, no identified studies leveraged emerging clinical risk factors, such as frailty, ${ }^{41,42}$ or biomarker data ${ }^{43,44}$ to enhance patient- or health professional-oriented personalized risk assessment.

Improving the quality of preoperative risk prediction and communication could positively impact patient care in a variety of ways. The decision-making process could be improved for patients, in particular by supporting shared decision making ${ }^{45}$ (a well-established means of providing patient-centred care and improving decisional quality for preference-sensitive healthcare decisions) ${ }^{46}$ of which personalized risk communication is a key component. ${ }^{47}$ Only one identified study combined personalized risk communication with shared decision-making, and showed considerable improvements in comprehension by patients. $^{23}$ Health system outcomes could also be improved through early identification of high-risk patients to allow individualized patient optimization and care planning. Identification of high-risk patients may decrease the length of hospital stay, ${ }^{24,25}$ however, based on methodologic limitations described below, these findings should be considered as hypothesis generating. 
Future studies evaluating the impact of personalized risk calculation and communication on patient- and systemcentred outcomes will need to address noteworthy methodologic limitations. Studies included in our review represented only 1,637 subjects and were heterogeneous in terms of processes employed and outcomes assessed. Only three studies featured an experimental design (i.e., where there was an intervention and comparator group); only one of these was a randomized trial. Therefore, to address the multiple knowledge gaps identified in this review, perioperative clinicians and researchers should focus on development of electronic risk calculation and communication processes that present predictions that would be understandable to patients, and which could support shared decision-making. Evaluation should include prospective studies using robust designs (such as randomized trials or interrupted time series) that are powered to address high priority patient- and systemoriented outcomes.

\section{Strengths and limitations}

Our search strategy was broad, peer-reviewed, and applied to multiple databases. We also followed well-established methods for scoping reviews, including iteration of our search to identify relevant studies. Studies were reviewed independently and in duplicate, and all data extraction was checked by an independent reviewer. Nevertheless, included studies were heterogeneous in terms of intervention types, study design, and outcomes, which limited opportunities for synthesis. Furthermore, we relied on abstracts for four of the seven included studies, which limits our ability to assess the processes used. Finally, we included only risk calculation and communication processes that were published in the scientific literature. Some electronic medical records may calculate risk scores in clinical practice, and many risk prediction applications are available through mobile information technology app stores; clinicians are likely using these applications or established risk scores in practice. Nevertheless, because most of these applications do not appear to have been scientifically evaluated, they were not included in our study.

\section{Conclusion}

Despite strong interest in personalized medicine, and an extensive literature showing that patients want to be better informed of their preoperative risk when making decisions, ${ }^{10,12,48}$ there is limited evidence of application of personalized risk calculation and communication. Existing evidence suggests that such applications could improve patient and system outcomes; nevertheless, weaknesses in study design limit the strength of these conclusions. Appropriately powered and designed evaluation of personalized perioperative risk communication is needed.

Acknowledgements We acknowledge the assistance of Ms. Sascha Davis, Learning Services, The Ottawa Hospital, for help with our search strategy and execution. Drs. Boet, Lalu, and McIsaac are supported by The Ottawa Hospital Anaesthesia Alternate Funds Association. Dr. Lalu is supported by the University of Ottawa Scholarship Protected Time Program. Dr. McIsaac is supported by the Canadian Anesthesiologists' Society Career Scientist Award and the University of Ottawa Junior Clinical Research Chair in Perioperative Health Systems and Outcomes Research.

Conflicts of interest and financial disclosures None declared.

Editorial responsiblity This submission was handled by Dr. Steven Backman, Associate Editor, Canadian Journal of Anesthesia.

Author contributions Daniel McIsaac, Emma Harris, and David MacDonald contributed to all aspects of this manuscript, including study conception and design; acquisition, analysis, and interpretation of data; and drafting the article. Laura Boland, Manoj Lalu, and Sylvain Boet contributed to the analysis and interpretation of data.

\section{Appendix A: MEDLINE search strategy}

1 Preoperative Period/ or Preoperative Care/ (65480)

2 (preoperative* or pre-operative* or presurg* or presurg* or prean?esth* or pre an?esth*).tw,kw. (300193)

3 (before adj2 operation*).tw,kw. (14177)

4 (before adj2 surgery).tw,kw. (41320)

5 or/1-4 (364317)

6 Risk Assessment/ (235064)

7 Surgical Procedures, Operative/ae or Anesthesia/ae (9978)

8 (surg* adj3 risk*).tw,kw. (26108)

9 (an?esth* adj3 risk*).tw,kw. (3360)

10 or/6-9 (269970)

11 Communication/ (77531)

12 Physician-Patient Relations/ (70140)

13 Counseling/ (34333)

14 Patient Education as Topic/ (82638)

15 Decision Support Techniques/ (18522)

16 decision aid*.tw,kw. (2577)

17 Decision Making/ (86672)

18 decision* support.tw,kw. (12032)

19 shared decision making.tw,kw. (5461)

20 (conversation* or discussion* or communication*).tw,kw. (491608) 
21 Informed Consent/ or (informed adj2 (consent or choice or decision*)).tw,kw. (67549)

22 or/11-21 (827848)

2310 and 22 (23764)

24 (risk* adj3 (notif* or inform* or communicat* or $^{*}$ counsel* or appraisal or assessment or perception* or perceiv*)).tw,kw. (90333)

2523 or $24(109195)$

265 and 25 (3435)

27 Patient-Centered Care/ (16132)

28 (patient centered or patient centred).tw,kw. (15912)

29 (patient* adj3 (involv* or engag* or inform* or preference* $^{*}$ or participat* or direct*)).tw,kw. (168412)

30 (personali?ed or individuali?ed or tailored or tailoring).tw,kw. (125664)

31 Patient Preference/ (6290)

32 or/27-31 (315205)

3326 and 32 (463)

\section{Appendix B: Reasons for exclusion of studies advanced to full-text review}

\begin{tabular}{ll}
\hline Reference & Reason for exclusion \\
\hline $\begin{array}{l}\text { Palenzia-Vizcarra } \text { et al., } \\
2016\end{array}$ & Review article \\
$\begin{array}{l}\text { Kavanagh and Blyth, } \\
2016\end{array}$ & No preoperative risk calculation \\
McNair et al., 2016 & Evaluation of standard consent process \\
Wong et al., 2015 & Audit of informed consent process \\
Whittle and Kelleher, & Review article \\
2015 & \\
Hardy et al., 2015 & No preoperative risk calculation \\
Burkle et al., 2014 & No preoperative risk calculation \\
Danielsen et al., 2014 & No preoperative risk calculation \\
Khoo et al., 2014 & Audit of informed consent documentation \\
Santini et al., 2013 & Guideline on preoperative information \\
Thirunkavarasu et al., & Description of mobile app development not \\
2014 & yet used \\
Lilic et al., 2011 & Review article \\
Stanley et al., 1998 & Evaluation of standard consent process \\
Ivarsson et al., 2005 & No preoperative risk calculation \\
Clark et al., 1990 & No preoperative risk calculation \\
Huber et al., 2013 & No preoperative risk calculation \\
Siu et al., 2015 & No preoperative risk calculation \\
\hline
\end{tabular}

Appendix C: Titles and brief descriptions of perioperative risk mobile applications available through Apple App Store and Google Play

1) Adult cardiac surgery Risk (Edward Bender)Estimates risk of morbidity and mortality following open cardiac surgery.

2) Risk assessment Tool for Spine Surgery Procedures (LogicThread Inc)_Estimates postoperative complications after spine surgery.

3) SORT The Surgical Outcome Risk Tool (Cranworth Medical Ltd)_Predicts mortality, adult, inpatient surgery (excludes obstetrics, neurosurgery, cardiac, transplant).

4) Goldman Cardiac Risk (Doctot)_Estimates cardiac risk of non-cardiac surgical patients, email generation of results.

5) Bariatric Surgery Calculator (Cleveland Clinic Innovations)_Compares different procedures' risk with patient characteristics.

6) EuroSCORE II (Edward Bender)_Estimates mortality from cardiac surgery.

7) CeDAR Carolina's Equation for Determining Associated Risks (Carolina's Surgical Innovation Group, LLC)—Predicts risk of financial impact and wound-related complications following ventral hernia repair.

8) RICS Readmission in Cardiac Surgery (USquare Soft Inc)_Predicts readmission for cardiac surgery.

9) Incisional Hernia Prediction (ValexConsulting Inc.)_Predicts surgically treated incisional hernia.

10) PJI calculator (Grace Shieh)_Estimates hip and knee periprosthetic joint infection recurrence.

11) Potter (Dimitris Bertsimas)_Emergency surgery risk calculator.

12) Perioperative Risk (Bruno Caramelli)_Estimates risk of complications for patients undergoing noncardiac surgery, and offers tips to reduce risk.

13) Preop Risk Assessment Tool (Blue Esoteric Web Development)_Evaluates multiple pre-operative risk scores including RCRI, RRI, SLIP, MICA.

14) P-Possum- JT Binary. Surgical Morbidity and Mortality Risk calculator based on physiological and surgical variables. Validated.

15) Preop (Physician cognition Inc)_Decision support tool for elective surgeries' risk, including RCRI.

16) Calculate by QxMD_-Predictive models for cardiac surgery and coronary angiography.

17) Cardio Calc (Dejan Gvozdanovic)_Calculates Lee Index (surgical risk for cardiac event and risk of preoperative cardiac events). 
18) Risk-E-Score (ICICOR Medical)_-Translated from Spanish. Predicts surgical risk associated with infective endocarditis.

19) Vizzielli's Score Calculator-Score to predict major postoperative complications after primary debulking surgery in advanced ovarian cancer.

20) SMATT score app (Valentina Favalli)_-Predicts risk of surgical in-hospital mortality through identification of predictors for personalized risk stratification.

21) BAR score (Rinicare)—British aneurysm repair score estimates in-hospital mortality risk for patients undergoing elective abdominal aortic aneurysm repair.

22) ADOPT-LC score (CureApp Inc)-Predicts postoperative in-hospital mortality based on four parameters in patients with liver cirrhosis.

\section{References}

1. Schleidgen S, Klingler C, Bertram T, Rogowski WH, Marckmann $G$. What is personalized medicine: sharpening a vague term based on a systematic literature review. BMC Med Ethics 2013; 14: 55.

2. Cesuroglu T, Syurina E, Feron F, Krumeich A. Other side of the coin for personalised medicine and healthcare: content analysis of 'personalised' practices in the literature. BMJ Open 2016; 6: $\mathrm{e} 010243$.

3. Ginsburg GS, Phillips KA. Precision medicine: from science to value. Health Aff (Millwood) 2018; 37: 694-701.

4. King A, Bottle A, Faiz $O$, Aylin P. Investigating adverse event free admissions in Medicare inpatients as a patient safety indicator. Ann Surg 2017; 265: 910-5.

5. Grewal K, Wijeysundera DN, Carroll J, Tait G, Beattie WS. Gender differences in mortality following non-cardiovascular surgery: an observational study. Can J Anesth 2012; 59: 255-62.

6. Wijeysundera DN, Beattie WS, Austin PC, Hux JE, Laupacis A. Non-invasive cardiac stress testing before elective major noncardiac surgery: population based cohort study. BMJ 2010; 340: b5526.

7. Bilimoria $K Y$, Liu $Y$, Paruch $J L$, et al. Development and evaluation of the universal ACS NSQIP surgical risk calculator: a decision aid and informed consent tool for patients and surgeons. J Am Coll Surg 2013; 217: 833-42.e1-3.

8. Varelius $J$. The value of autonomy in medical ethics. Med Health Care Philos 2006; 9: 377-88.

9. Leclercq WK, Keulers BJ, Scheltinga MR, Spauwen PH, van der Wilt GJ. A review of surgical informed consent: past, present, and future. A quest to help patients make better decisions. World $\mathrm{J}$ Surg 2010; 34: 1406-15.

10. Keulers BJ, Scheltinga MR, Houterman S, Van Der Wilt GJ, Spauwen PH. Surgeons underestimate their patients' desire for preoperative information. World J Surg 2008; 32: 964-70.

11. Taher T, Khan NA, Devereaux PJ, et al. Assessment and reporting of perioperative cardiac risk by Canadian general internists: art or science? J Gen Intern Med 2002; 17: 933-6.

12. Gainer RA, Curran J, Buth KJ, David JG, Légaré JF, Hirsch GM. Toward optimal decision making among vulnerable patients referred for cardiac surgery: a qualitative analysis of patient and provider perspectives. Med Decis Mak 2017; 37: 600-10.

13. Mulley AG Jr. The role of shared decision making in achieving allocative efficiency in health systems. In: Elwyn G, Edwards A, Thompson R, editors. Shared Decision Making in Healthcare: Achieving Evidence-Based Patient Choice. 2nd ed. Oxford, UK: Oxford University Press; 2016 .

14. Gattellari M, Ward JE. Will men attribute fault to their GP for adverse effects arising from controversial screening tests? An Australian study using scenarios about PSA screening. J Med Screen 2004; 11: 165-9.

15. Wijeysundera $D N$. Predicting outcomes: is there utility in risk scores? Can J Anesth 2015; 63: 148-58.

16. Levac D, Colquhoun H, O'Brien KK. Scoping studies: advancing the methodology. Implement Sci 2010; 5: 69.

17. Tricco AC, Lillie E, Zarin W, et al. PRISMA Extension for Scoping Reviews (PRISMA-ScR): checklist and explanation. Ann Intern Med 2018; 169: 467-73.

18. Arksey H, O'Malley L. Scoping studies: towards a methodological framwork. Int J Soc Res Methodol 2005; 8: 1932.

19. Stiefel M, Nolan K. A Guide to Measuring the Triple Aim: Population Health, Experience of Care, and Per Capita Cost. Institute for Healthcare Improvement. Cambridge, MA; 2012. Available from URL: http://www.ihi.org/resources/Pages/ IHIWhitePapers/AGuidetoMeasuringTripleAim.aspx (accessed March 2019).

20. McGowan J, Sampson M, Salzwedel DM, Cogo E, Foerster V, Lefebvre $C$. PRESS peer review of electronic search strategies: 2015 guideline statement. J Clin Epidemiol 2016; 75: 40-6.

21. Levac D, Colquhoun H, O'Brien KK. Scoping studies: advancing the methodology. Implement Sci 2010; 5: 69.

22. Malenka DJ, Ross CS, Langner C, et al. Can a Customized quantitative informed consent document improve decision quality and be integrated into the routine process of care Circulation 2011; 4: P308 (abstract).

23. Gainer R, Begum J, Wilson-Pease E, Hirsch G. A formalized shared decision making process with individualized decision aids improves comprehension and decisional quality among frail, elderly cardiac surgery patients. Can J Cardiol 2016; 32: S266-7.

24. MacDonald V, Arthur B, Parent $S$. The Vancouver General Hospital joint replacement rapid recovery program: optimizing outcomes through focused pathways. J Orthop Nurs 2005; 9: 95102.

25. Punt IM, van der Most R, Bongers BC, et al. Improving pre- and perioperative hospital care: major elective surgery (German) Bundesgesundheitsblatt Gesundheitsforschung Gesundheitsschutz 2017; 60: 410-8.

26. Miranne JM, Gutman RE, Sokol AI, Park AJ, Iglesia CB. Effect of a new risk calculator on patient satisfaction with the decision for concomitant midurethral sling during prolapse surgery: a randomized controlled trial. Female Pelvic Med Reconstr Surg 2017; 23: 17-22.

27. Aggarwal S, Stewart P, Eccersley J. Use of real time mortality risk assessment to inform standard of sugical care in a District General Hospital. Color Dis 2014; 116: 169.

28. Bihorac A, Cobb R, Wang DZ, et al. Computer algorithms are superior to physician assessment of the risk for postoperative complications. Crit Care Med 2013; DOI: https://doi.org/10.1097/ 01.ccm.0000439930.22840.bc.

29. Moonesinghe SR, Mythen MG, Das P, Rowan KM, Grocott MP. Risk stratification tools for predicting morbidity and mortality in adult patients undergoing major surgery: qualitative systematic review. Anesthesiology 2013; 119: 959-81.

30. Oliver CM, Walker E, Giannaris S, Grocott MP, Moonesinghe $S R$. Risk assessment tools validated for patients undergoing 
emergency laparotomy: a systematic review. Br J Anaesth 2015; 115: 849-60.

31. Jelovsek JE, Chagin K, Brubaker L, et al. A model for predicting the risk of de novo stress urinary incontinence in women undergoing pelvic organ prolapse surgery. Obstet Gynecol 2014; 123(2 Pt 1): 279-87.

32. Ford MK, Beattie WS, Wijeysundera DN. Systematic review: prediction of perioperative cardiac complications and mortality by the revised cardiac risk index. Ann Intern Med 2010; 152: 2635 .

33. Ahmed H, Naik G, Willoughby H, Edwards AG. Communicating risk. BMJ 2012; 344: e3996.

34. Neuner-Jehle S, Senn O, Wegwarth O, Rosemann T, Steurer J. How do family physicians communicate about cardiovascular risk? Frequencies and determinants of different communication formats. BMC Fam Pract 2011; 12: 15.

35. Wegwarth O, Schwartz LM, Woloshin S, Gaissmaier W, Gigerenzer G. Do physicians understand cancer screening statistics? A national survey of primary care physicians in the United States. Ann Intern Med 2012; 156: 340-9.

36. Trevena LJ, Davey HM, Barratt A, Butow P, Caldwell P. A systematic review on communicating with patients about evidence. J Eval Clin Pract 2006; 12: 13-23.

37. Harrell FE, Lee KL, Mark DB. Multivariable prognostic models: issues in developing models, evaluating assumptions and adequacy, and measuring and reducing errors. Stat Med 1996; 15: $361-87$.

38. Fagerlin A, Zikmund-Fisher BJ, Ubel PA. Helping patients decide: ten steps to better risk communication. J Natl Cancer Inst 2011; 103: 1436-43.

39. Zikmund-Fisher BJ, Ubel PA, Smith DM, et al. Communicating side effect risks in a tamoxifen prophylaxis decision aid: the debiasing influence of pictographs. Patient Educ Couns 2008; 73: 209-14.
40. Edwards AG, Naik $G$, Ahmed $H$, et al. Personalised risk communication for informed decision making about taking screening tests. Cochrane Database of Syst Rev 2013; 2: CD001865.

41. Beggs T, Sepehri A, Szwajcer A, Tangri N, Arora RC. Frailty and perioperative outcomes: a narrative review. Can J Anesth 2015; 62: 143-57.

42. Lin HS, Watts JN, Peel NM, Hubbard RE. Frailty and postoperative outcomes in older surgical patients: a systematic review. BMC Geriatr 2016; 16: 157.

43. Rodseth RN, Lurati Buse GA, Bolliger D, et al. The predictive ability of pre-operative B-type natriuretic peptide in vascular patients for major adverse cardiac events: an individual patient data meta-analysis. J Am Coll Cardiol 2011; 58: 522-9.

44. Nan J, Li J, Li X, Guo G, Wen X, Tian Y. Preoperative serum carcinoembryonic antigen as a marker for predicting the outcome of three cancers. Biomark Cancer 2017; 9: 1-7.

45. Moulton BW, Pope TM. Emerging legal issues for providers in the US. In: Elwyn G, Edwards A, Thompson R, editors. Shared Decision Making in Healthcare: Achieving Evidence-Based Patient Choice. 2nd ed. Oxford, UK: Oxford University Press; 2016 .

46. Barry MJ, Edgman-Levitan S. Shared decision making-pinnacle of patient-centered care. N Engl J Med 2012; 366: 780-1.

47. Hargraves I, LeBlanc A, Shah ND, Montori VM. Shared decision making: the need for patient-clinician conversation, not just information. Health Aff (Millwood) 2016; 35: 627-9.

48. Joseph-Williams $N$, Elwyn $G$, Edwards A. Knowledge is not power for patients: a systematic review and thematic synthesis of patient-reported barriers and facilitators to shared decision making. Patient Educ Couns 2014; 94: 291-309.

Publisher's Note Springer Nature remains neutral with regard to jurisdictional claims in published maps and institutional affiliations. 